\title{
TESTING SEPARATION CHAMBER OF PNEUMATIC SYSTEM IN FRACTIONAL GRAIN PRETREATMENT MACHINE
}

\author{
Andrey Glushkov, Aleksandr Burkov \\ Federal Agricultural Research Center of the North-East named N.V. Rudnitsky, Russia \\ glandreas79@gmail.com, burkov.46@mail.ru
}

\begin{abstract}
The paper analyzes the separation of heaps in the separation chamber of the pneumatic system in a fractional grain pretreatment machine. The finding is that the components of feed grain may reach the sedimentation chamber. A reflective partition must be in place to fully capture them in the separation chamber. The paper analyzes the estimated trajectories of grain particles of various grains to optimally position the front edge of this partition. The Selma feed oats are found to be moving the closest to the outer wall, which is why their trajectories define where the front edge of the reflective partition must be. When placing the front edge of the reflective partition at $0.25 \mathrm{~m}$ off the outer wall of the pneumatic system, the vertical setpoint is $0.515 \mathrm{~m}$. To confirm the theoretical findings, the research team conducted experiments to find out the exact vertical and depthwise distribution of grain components in the separation chamber. The experiments used a laboratory bench version of the pneumatic system like those used in grain pretreatment machines. For experiments, the team prepared a grain mix that comprised Abava barley grains (50\% large-particle grains, $45 \%$ small-particle grain) $+5 \%$ of light impurities. The experiments showed that to prevent the grain from infiltrating in the dust exhaust located between the reflective partition and the outer wall, the front edge of the partition must be set at 0.47 to $0.55 \mathrm{~m}$ vertically, $0.25 \ldots 0.30 \mathrm{~m}$ off the outer wall, which confirms the estimates.
\end{abstract}

Keywords: separation chamber, pneumatic separation channel, grain, light impurities, airflow.

\section{Introduction}

The most important task in the agricultural sector is the production of grain for seed, food and feed purposes. Ensuring the safety of the harvested crop and bringing it to marketable products depends on the level of mechanization of post-harvest processing and storage of grain [1].

In post-harvest processing of grain heaps, the flow-line grain treatment technology is mainly used [2]. It involves passing the entire multicomponent grain heap through several sequentially installed grain treatment machines for various purposes. Its disadvantages $[1 ; 2]$ :

1. Underutilization of the power of individual machines and equipment, since the maximum performance of a line running on a flow-line technology is determined by a machine, which performance in these conditions is minimal;

2. Drying of feed grain in a single stream with the seed grain, which increases the load on the seed grain dryer, reducing its performance and work efficiency;

3. Incompleteness of the process in terms of quality indicators due to the lack of special machines and low efficiency of grain treatment machines, which causes the need to repeatedly pass the same amount of grain heap through the same machines.

Increasing the number of passes to achieve the required quality of seeds for purity increases the degree of their injury, which is one of the main reasons for reducing yields.

One important way to improve the quality of grain treatment is to separate it by fractionation, which makes use of various physical and mechanical properties. Researchers and companies in a number of countries develop and produce grain treatment machines that provide for the separation of grain material into fractions [3-6]. Separating a grain heap into seed and feed by airflow helps isolate the most productive seeds, improves the production line performance, and reduces damage to the grains [7-9].

\section{Materials and methods}

For pneumatic fractionation of harvested grain, the Federal Agricultural Research Center of the North-East named N.V. Rudnitsky has developed a grain treatment machine that contains a pneumatic separator and a three-level sieving mill [10].

The pneumatic separator shown in Fig. 1 uses an open circuit and consists of: a feeding roller 1, an inclined pneumatic separation channel 2 , a loader-distributor 4 , a reflective plane 6 , a diametral fan 
8 , and airflow controller 9 , an exhaust pipe 10 , a sedimentation chamber 11 , and a separation chamber 14, which splits into two outlets for particles of different size 12 and 15.

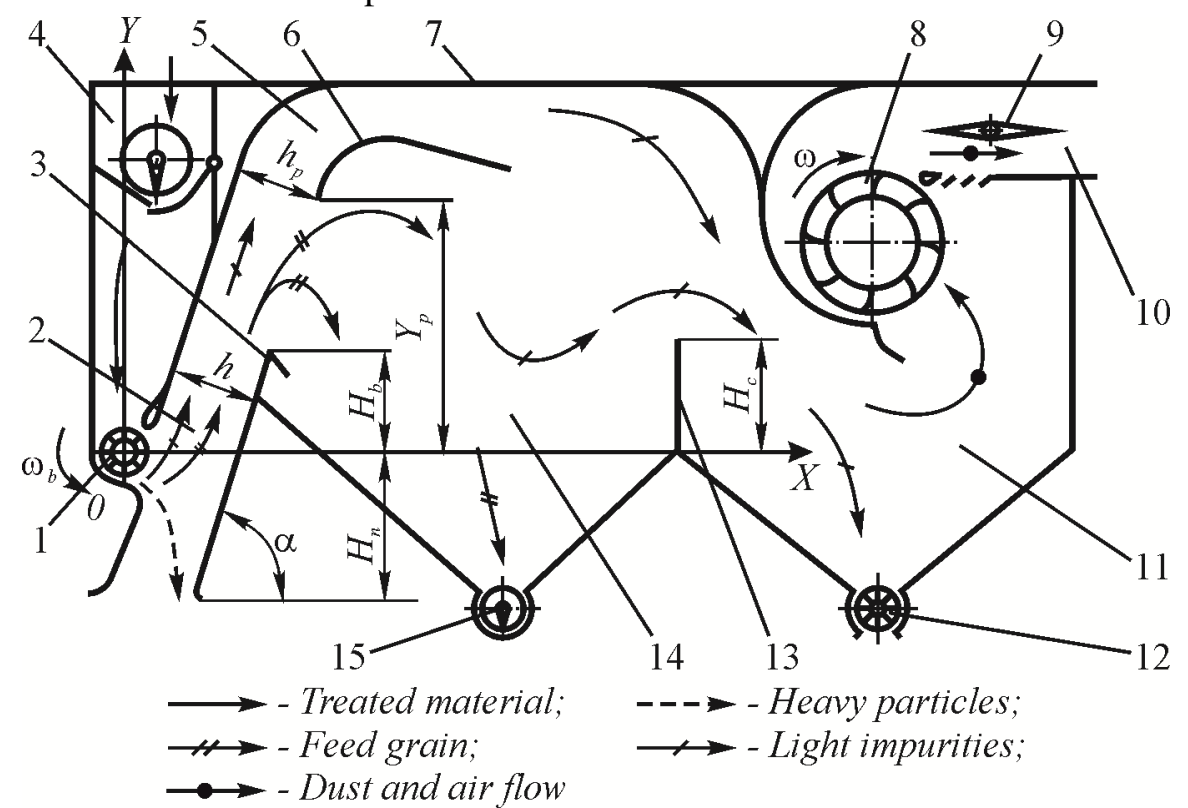

Fig. 1. Pneumatic separator diagram: 1 - feeding roller; 2 - inclined pneumatic separation channel;

3 - wall between 2 - and the separation chamber; 4 - loader-distributor; 5 - dust exhaust;

6 - reflective plane; 7 - upper wall; 8 - diametral fan; 9 - airflow controller; 10 - exhaust pipe;

11 - sedimentation chamber; 12,15 - outlets for particles of different size; 13 - wall between the separation chamber and the sedimentation chamber; 14 - separation chamber

The pneumatic separator functions as follows. The loader-distributor 4 drives an auger to evenly distribute the input heap across the pneumatic separator; the heap is further fed to the feeding roller 1 , which feeds it to the inclined pneumatic separation channel 2 . The diametral fan 8 induces an airflow controlled by the airflow controller 9; in the pneumatic separation channel 2, this airflow captures the light impurities and carries through the dust exhaust 5 formed by the upper wall 7 of the pneumatic system and the reflective plane 6. The impurities end up in the sedimentation chamber 11. Light impurities settled in the chamber 11 are excreted by the outlet 12 .

Crushed, shriveled, or small grains (all constituting the feed grain) have a greater critical terminal velocity than the light impurities; as they pass under the reflective plane 6 , the inertial and gravitational forces force them to settle in the separation chamber 14, where the outlet 15 forces them out. Feed grain may account for $30 \%+$ of the heap. The diametral fan 8 forces the airflow from the sedimentation chamber 11 to go through the exhaust pipe 10 to the dust filter (not shown). Gravity forces heavy grain out of the pneumatic separation channel 2.

In the course of separation, some of the feed grain components may mix with the light impurities and end up in the sedimentation chamber 11 . To capture more of them, the front edge of the reflective plane 6 of the separation chamber 14 must be optimized positionally.

The goal hereof is to find analytically and experimentally the optimal front edge position with respect to the feeding roller and the outer wall of the pneumatic system.

The research presented herein was both analytical and experimental. The theoretical research was based on the known classical mechanics and aerodynamics laws, as well as on the Runge-Kutta method for discretization of differential equations [11-13].

Pursuant to the theory of turbulent jets, the airflow in the separation chamber could be represented as a semi-limited turbulent jet of an incompressible fluid [11]. Apply these theories to find the trajectories of grain particles in a separation chamber. To that end, assume that: the jet substance is incompressible; the boundary layer on either boundary of the jet starts to develop in the initial section 1 at the outlet of the pneumatic separation channel, see Fig. 2a; the section, where the jet boundary layer 4 interfaces with the wall boundary layer 2 , is where the initial flow segment ends and the 
primary segment begins; the airflow speed in the initial jet section $1 V_{b 0}=$ const; the airflow velocity beyond the jet 5 is $V_{b}=0$.
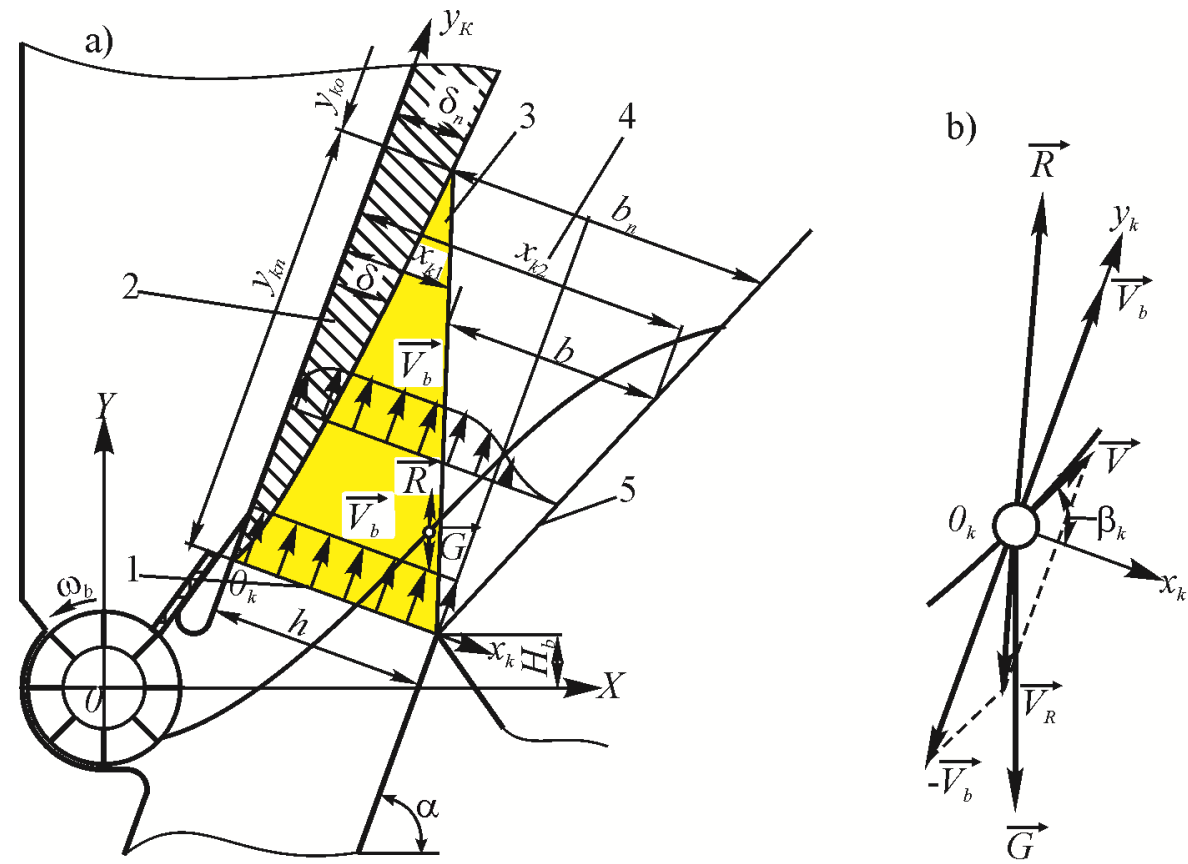

Fig. 2. Diagram of airflow formed by the semi-limited turbulent jet (a); diagram of forces acting on a moving particle in the separation chamber (b): 1 - initial jet section; 2 - wall boundary layer; 3 - constant velocity core; 4 - jet boundary layer; 5 - jet boundary

Consider the initial segment of the semi-limited turbulent jet in the $x_{k} 0_{k} y_{k}$ coordinate system, see Fig. 2a. Represent the velocity profile in each cross-section of the initial segment by three mathematical dependencies $[11 ; 12]$.

In the domain $0<x_{k}<\delta$, the velocity profile can be described by the equation:

$$
V_{b}=\left(\frac{x_{k}}{\delta}\right)^{1 / 7} \cdot V_{b 0},
$$

where $\delta$-wall boundary layer thickness, $\mathrm{m}$;

Assume that the velocity is constant in the domain $\delta \leq x_{k} \leq x_{k 1}$ and equals:

$$
V_{b}=V_{b 0} \text {; }
$$

In the domain $x_{k 1}<x_{k}<x_{k 2}$, the velocity profile is approximated by the equation:

$$
V_{b}=\left[1-\left(\frac{x_{k}-x_{k 1}}{b}\right)^{3 / 2}\right]^{2} \cdot V_{b 0},
$$

where $x_{k 1}-$ inner boundary of the jet boundary layer, $\mathrm{m}$;

$b-$ thickness of the jet boundary layer, $m$.

A particle moving in the separation chamber is affected by the gravity $\vec{G}$ directed vertically downwards, see Fig. 2 b; and by the airflow resistance force $\vec{R}$ that is directed against the relative velocity $\vec{V}_{R}$ of the particle. The basic equation of the material point dynamics is written as:

$$
m \cdot \vec{a}=\vec{R}+\vec{G},
$$

where $m$-particle mass, $\mathrm{kg}$;

$a$ - particle acceleration, $\mathrm{m} \cdot \mathrm{s}^{-2}$. 
Projecting onto the selected coordinate axes $O_{k} x_{k}$ and $O_{k} y_{k}$ produces a system of differential equations:

$$
\left\{\begin{array}{l}
m \cdot \ddot{x}_{k}=R_{x k}+G \cdot \cos \alpha ; \\
m \cdot \ddot{y}_{k}=R_{y k}-G \cdot \sin \alpha,
\end{array}\right.
$$

where $R_{x k}=-m \cdot k_{p} \cdot V_{R} \cdot V_{R x k}$ and $R_{y k}=-m \cdot k_{p} \cdot V_{R} \cdot V_{R y k}$ - projections of the airflow resistance force $R$ onto the coordinate axes;

$\alpha$ - angle between the airflow velocity vector and the horizontal, deg;

$k_{p}$ - windage factor, $\mathrm{m}^{-1}$;

$V_{R}$ - modulus of relative velocity, $\mathrm{m} \cdot \mathrm{s}^{-1}$;

$V_{R x k}$ and $V_{R y k}$ - projections of relative velocity onto the coordinate axes.

Appropriate transformations return:

$$
\left\{\begin{array}{l}
\ddot{x}_{k}=k_{p} \cdot \dot{x}_{k} \cdot \sqrt{\dot{x}_{k}^{2}+\left(\dot{y}_{k}-V_{b}\right)^{2}}+g \cdot \cos \alpha ; \\
\ddot{y}_{k}=-k_{p} \cdot\left(\dot{y}_{k}-V_{b}\right) \cdot \sqrt{\left(\dot{x}_{k}^{2}+\left(\dot{y}_{k}-V_{b}\right)^{2}\right.}-g \cdot \sin \alpha .
\end{array}\right.
$$

To solve the system of differential equations (6), substitute the airflow velocity found from (1), (2), and (3), depending on where the particle is positioned in the semi-limited turbulent jet at the time.

This system of second-order differential equations does not have an exact analytical solution, even if the airflow velocity $V_{b}$ is constant. Therefore, its numerical solution should be found by the Runge-Kutta method [9]. Reduce the system (15) to four first-order differential equations $\dot{x}_{k}=A_{k}$ and $\dot{y}_{k}=B_{k}$, obtaining:

$$
\left\{\begin{array}{l}
\dot{A}_{k}=k_{p} \cdot A_{k} \cdot \sqrt{A_{k}^{2}+\left(B_{k}-V_{b}\right)^{2}}+g \cdot \cos \alpha ; \\
\dot{x}_{k}=A_{k} \\
\dot{B}_{k}=-k_{p} \cdot\left(B_{k}-V_{b}\right) \cdot \sqrt{A_{k}^{2}+\left(B_{k}-V_{b}\right)^{2}}-g \cdot \sin \alpha ; \\
\dot{y}_{k}=B_{k} .
\end{array}\right.
$$

Before solving the system (7), add initial conditions: $t_{0}=0 ; x_{k 0}=x_{k i} ; y_{k 0}=0 ; \dot{x}_{k 0}=V_{i} \cdot \cos \beta_{k i}$; $\dot{y}_{k 0}=V_{i} \cdot \sin \beta_{k i}$, where $x_{k i}$ is the position of the $i$ th particle in the section when leaving the pneumatic separation channel, $\mathrm{m} ; V_{i}$ is the absolute velocity of the $i$ th particle when leaving the pneumatic separation channel, $\mathrm{m} \cdot \mathrm{s}^{-1} ; \beta_{k i}$ is the angle between the absolute particle velocity and the $O_{k} x_{k}$ axis, deg.

Find the trajectories of feed grains in the separation chamber, which have a maximum windage factor $k_{p}=k_{p \text {.max }}$. Trajectories were computed for such airflow velocity in the initial jet section (in the pneumatic separation channel) that was equal to the minimum terminal velocity of full-size, nondefective grain $V_{b}=V_{v \cdot \min }$, for channel depth $h=0.25 \mathrm{~m}$. The edge of the wall between the pneumatic channel and the separation chamber was set experimentally, estimated as $H_{b}=0.05 \mathrm{~m}$. Trajectories of feed grains in the separation chamber were found in the $X O Y$ coordinate system.

Basic common methods were used for experimental research of vertical and depthwise distribution of initial grain components in the separation chamber; the laboratory bench did not have the reflective plane 6 (Fig. 1), while the process parameters of the pneumatic system were constant: pneumatic separation channel depth $h=0.25 \mathrm{M}$; upper channel height $H_{b}=0.05 \mathrm{~m}$; separation/sedimentation chamber wall height $H_{c}=0.50 \mathrm{~m}$; feeding roller speed $n=115 \mathrm{~min}^{-1}$; channel inclination $\alpha=80^{\circ}$ [14]. For studies, the specific grain feed rate was set to $8.6 \pm 0.1 \mathrm{~kg} \cdot \mathrm{s}^{-1} \cdot \mathrm{m}^{-1}$. Waste of full-size, non-defective grain was maintained at $0.05 \pm 0.001 \%$ in all experiments.

For experiments, the team prepared a grain mix that comprised Abava barley grains (50\% largeparticle grains, $45 \%$ small-particle grain) $+5 \%$ of light impurities; the moisture content was $14 \%$. The material was separated into large and small grains, using a sieve with $2.8 \mathrm{~mm}$ rectangular holes. For light impurities, the team used wooden sawdust, as its aerodynamic properties were found similar 
to those of light impurities normally found in Abava barley grain heaps. The sawdust was sieved through a sieve with $1.7 \mathrm{~mm}$ wide oblong rectangular holes.

Light impurities could be fully extracted at airflow velocities in the separation zone of at least $5.0 \mathrm{~m} \cdot \mathrm{s}^{-1}$. The material is best separated into small and large grains at the airflow velocity $V_{b}=9.4-$ $9.8 \mathrm{~m} \cdot \mathrm{s}^{-1}$.

The experiments used a 6-segment sampler with two covers. For experimentation, the researchers set the sampler at different vertical setpoints in the separation chamber. Figure 3 shows the sampler installation diagram.

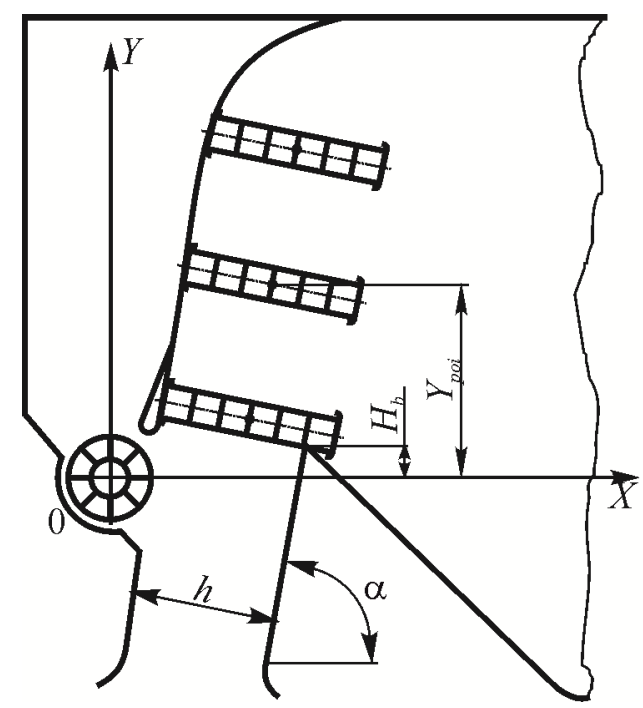

Fig. 3. Sampler installation diagram

To estimate the vertical and depthwise distribution of grain components in the separation chamber, the researchers used the relative mass $\left(a_{l i}\right.$ for light impurities and $a_{z i}$ for grain) that the components in each sampler segment had; these were found by the formulas:

$$
a_{l i}=\frac{m_{l i}}{m_{l p}} \cdot 100, \%,
$$

where $m_{l i}-$ mass of light impurities in the ith sampler segment, g;

$m_{l p}-$ total mass of light impurities in the sampler, $\mathrm{g}$.

$$
a_{z i}=\frac{m_{z i}}{m_{z p}} \cdot 100, \%,
$$

where $m_{z i}$ - mass of grain in the ith sampler segment, $\mathrm{g}$; $m_{z p}$ - total mass of grain in the sampler, $\mathrm{g}$.

\section{Results and discussion}

Figure 4 shows the calculated trajectories of feed grains of barley, winter rye, oats, and wheat in the separation chamber. The dependencies show that the Selma oat grains move the closest to the outer wall at $k_{p}=3.13 \mathrm{~m}^{-1}$ with the pneumatic separation channel airflow velocity $V_{b 0}=5.1 \mathrm{~m} \cdot \mathrm{s}^{-1}$. This leads to a conclusion that it is the Selma oat trajectories that will determine the position of the front edge of the reflective plane. Thus, if the front edge is set at the pneumatic separation channel depth $h_{p}=h=0.25 \mathrm{~m}$ off the outer wall, its vertical setpoint is $Y_{p}=0.515 \mathrm{~m}$ off the feeding roller.

If the front edge is set farther off the outer wall, some of the feed grains (oat) will infiltrate in the dust exhaust 5 shown in Fig. 1, which is between the upper wall 7 of the pneumatic system and the reflective plane 6; the exhaust will carry it to the sedimentation chamber 11, where light impurities settle. If the front edge is set closer to the outer wall, most of the light impurities will pass under the reflective plane and settle in the separation chamber 14, thus jeopardizing the filtering performance. 
The vertical setpoint of the front edge also determines the airflow through the dust exhaust and through the separation chamber. Setting the front edge lower will reduce the airflow through the separation chamber, thus jeopardizing the removal of light impurities from the separation chamber into the sedimentation chamber. Setting it higher will reduce the airflow through the dust exhaust, which might cause some of the light impurities to stay on the inner wall of the exhaust, i.e. on the reflective plane.

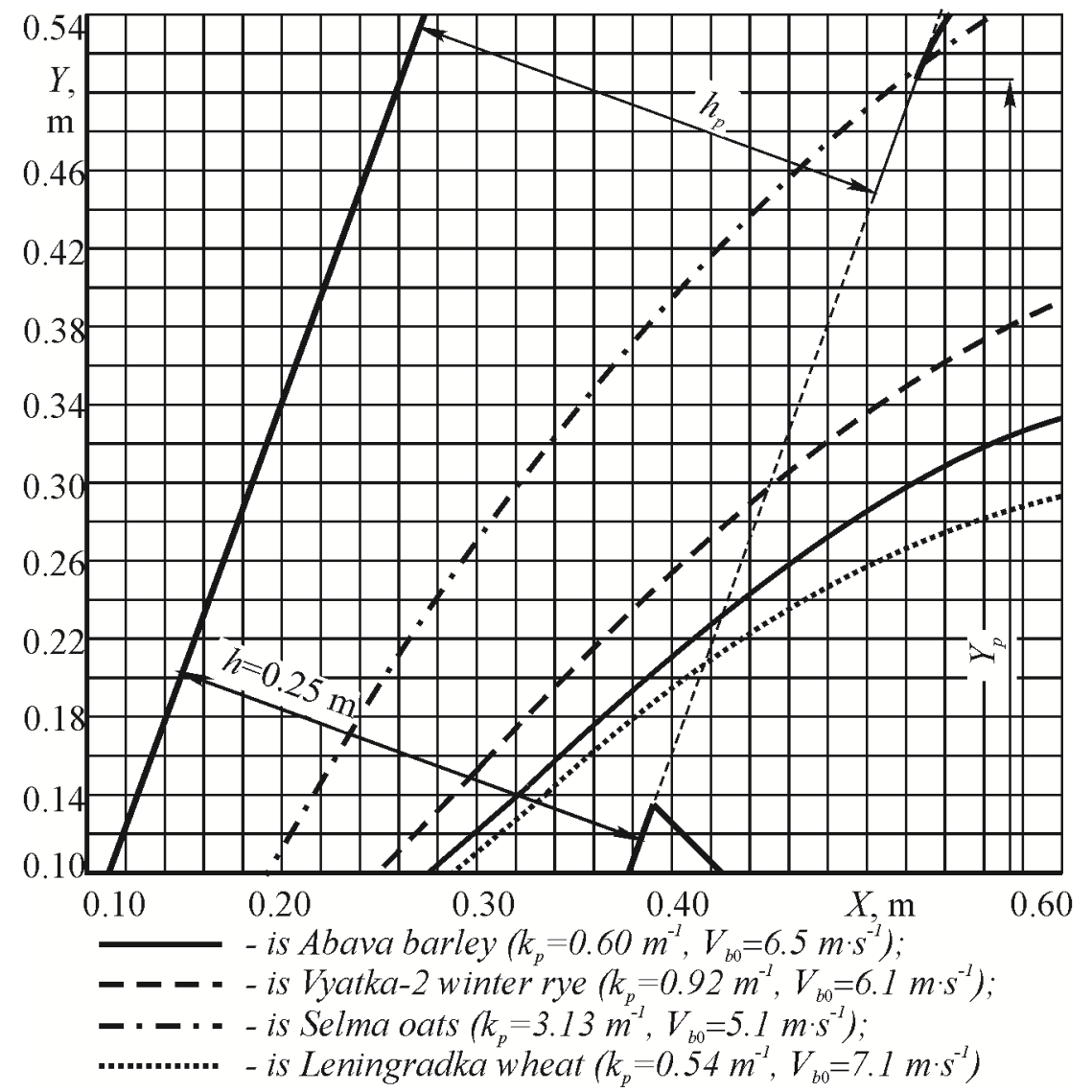

Fig. 4. Trajectories of feeder grains in the separation chamber

Table 1 shows the experimentally found vertical and depthwise distribution of grain in the separation chamber.

Table 1

Depthwise and vertical distribution of the grain components in the separation chamber

\begin{tabular}{|c|c|c|c|c|c|c|c|c|c|c|c|c|}
\hline \multirow{3}{*}{$\begin{array}{c}\text { Vertical setpoint } \\
\text { of the sampler } \\
Y_{p 0}, \mathrm{~m}\end{array}$} & \multicolumn{6}{|c|}{ Light impurities $a_{l i}, \%$} & \multirow{2}{*}{\multicolumn{6}{|c|}{$\begin{array}{c}\text { Grain } a_{z i}, \% \\
\text { Sampler segment \# }\end{array}$}} \\
\hline & \multicolumn{6}{|c|}{ Sampler segment \# } & & & & & & \\
\hline & 1 & 2 & 3 & 4 & 5 & 6 & 1 & 2 & 3 & 4 & 5 & 6 \\
\hline 0.095 & - & 1.5 & 6.6 & 29.8 & 62.1 & - & - & - & 3.5 & 23.6 & 72.9 & - \\
\hline 0.220 & - & - & 1.1 & 5.9 & 29.2 & 63.8 & - & - & - & 3.2 & 22.0 & 74.8 \\
\hline 0.345 & - & - & - & 2.5 & 23.5 & 74.0 & - & - & - & - & 8.9 & 91.1 \\
\hline 0.470 & - & & & & 15.0 & 85.0 & - & - & - & - & - & 100 \\
\hline 0.595 & - & - & - & - & 5.5 & 94.5 & - & - & - & - & - & - \\
\hline
\end{tabular}

After installing the sampler in the separation chamber at $Y_{p 0}=0.095 \mathrm{~m}$, light impurities distribute as follows in four segments: Segment $2 a_{l 2}=1.5 \%$; Segment $3 a_{l 3}=6.6 \%$; Segment $4 a_{l 4}=29.8 \%$, and Segment $5 a_{15}=62.1 \%$. Grain distributes in three segments: Segment $3 a_{z 3}=3.5 \%$; Segment 4 $a_{z 4}=23.6 \%$, and Segment $5 a_{z 5}=72.9 \%$. The sixth segment of the sampler is inactive, as it overlaps with the shared separation channel/separation chamber wall.

A different depthwise distribution of grain material in the separation chamber is observed at higher sampler setpoints. Most of the light impurities and grain shifts towards the separation chamber 
(Segments 5 and 6). At $Y_{p 0}=0.595 \mathrm{~m}$ light impurities distribute in two segments: Segment 5 $a_{l 5}=5.5 \%$ and Segment $6 a_{16}=94.5 \%$. In this case, all grain goes to the separation chamber, and no grain ends up in the sampler.

The finding is therefore as follows: to prevent the grain from entering the dust exhaust and to divert most of the light impurities to that exhaust, the front edge of the reflective plane must be set at $Y_{p}=0.47-0.55 \mathrm{~m}$ vertically and $h_{p}=0.25-0.30 \mathrm{~m}$ off the outer wall of the pneumatic separation channel.

\section{Conclusions}

1. The researchers analyzed the estimated trajectories various grains would follow in the separation chamber; the analysis identified the best position for the front edge of the reflective plane: $Y_{p}=0.515 \mathrm{~m}$ vertically off the feeding roller, with the dust exhaust depth $h_{p}=h=0.25 \mathrm{~m}$.

2. The conducted experiments show that to prevent the grain from infiltrating in the dust exhaust located between the reflective partition and the outer wall, the front edge of the partition must be set at 0.47 to $0.55 \mathrm{~m}$ vertically, $0.25 \ldots . .0 .30 \mathrm{~m}$ off the outer wall, which confirms the estimates.

\section{References}

[1] Rudnev S.G. Principles of organization of post-harvest grain processing. International scientific and practical conference world science, Vol. 2, 2017, No 4(20), pp. 16-19.

[2] Дринча В.M. Исследование сепарации семян и разработка машинных технологий их подготовки (Grain cleaning and Technology Hardware for seeds Preparation). Voronezh: NPO "Modek", 2006, 382 p. (In Russian).

[3] Panasiewicz M., Zawiślak K., Kusińska E., Sobczak P. Purification and separation of loose materials in a pneumatic system with vertical air stream. TEKA Kom. Mot. Energ. Roln. - OL PAN, 2008, Vol. 8, pp.171-176.

[4] Mikhailov E., Zadosnaia N., Rubtsov N., Kangalov P. Methodology for determining the parameters of the air flow in a pneumatic separator with a closed air system. Journal of Agriculture and Environment, 2017, 1 (1). pp. 35-40.

[5] Innovative solutions and technologies for the grain milling industry. BÜHLER Solutions and Technologies, 2013, 23 p. [online] [28.04.2020]. Available at: https://former.buhlergroup.com/china/zh/downloads/Brochure_Top_Line_Milling_2013_EN.pdf

[6] PETKUS Technologie GmbH. Products Sorting. Cleaners. [online] [28.04.2020]. Available at: http://www.petkus.com/products/-/info/sorting/cleaners.

[7] Пивень В.В., Уманская О.Л. Основные тенденции совершенствования фракционных технологий очистки зерна (Major trends improving fractional technology grain cleaning). Problems of modern science and education, 2013, No 1(15), pp. 39-43 (In Russian).

[8] Оробинский В.И. Фракционирование зерна. Совершенствование послеуборочной обработки семян (Grain fractionation. Improvement of postharvest seed treatment). Germany, Saarbrucken: LAP Lambert Academic Publishing, 2012, 380 p. (In Russian).

[9] Gievsky A. M., Orobinsky V. I., Tarasenko A. P., Chernyshov A. V., Kurilov D. O. Substantiation of basic scheme of grain cleaning machine for preparation of agricultural crops seeds. IOP Conference Series: Materials Science and Engineering, 2018, 327: 042035.

[10]Бурков А.И., Глушков А.Л. Машина предварительной очистки зерна (Machine for preliminary grain cleaning). Selskiy Mechanizator, 2007, No 1, pp. 8 (In Russian).

[11] Абрамович Г.Н. Теория турбулентных струй (Theory of turbulent jets). Moscow: Fizmatizdat, 1960, 715 p. (In Russian).

[12] Идельчик И.Е. Аэрогидродинамика технологических аппаратов (Aerohydrodynamics of technological devices). Moscow: Mashinostroyeniye, 1983, 351 p. (In Russian).

[13] Сысуев В.А., Алешкин А.В., Кормщиков А.Д. Методы механики в сельскохозяйственной технике (Methods of mechanics in agricultural machinery). Kirov: Agricultural Research Institute of North-East, 1997, 218 p. (In Russian).

[14]Кошурников А.Ф. Основы научных исследований (Basics of scientific research). Perm: IPC "Prokrost", 2014, 317 p. (In Russian). 